\title{
A Study on Impact of the Time Lapse from Onset of Symptoms in Acute Cholecystitis to Laparoscopic Cholecystectomy on outcome
}

\author{
Viswanath Nallapaneni ${ }^{1}$, Sree Ram Gokanapudi ${ }^{2}$, A Satish Babu ${ }^{3}$
}

\begin{abstract}
One third of the patients with acute cholecystitis present beyond 72 hours and due to various reasons are managed conservatively with interval cholecystectomy to follow. There is an increased total hospitalization and subsequently increased cost in these patients. Furthermore, the subgroup of patients who do not respond to conservative treatment, as well as those who relapse while awaiting an interval cholecystectomy should be considered for early cholecystectomy. For these reasons, a policy of performing a $L C$ during the initial emergency/urgent admission for "all comers" with AC, regardless of time delay between its onset of symptoms and surgery was adopted. In view of this policy, we examined prospectively the impact of the duration of symptoms on mortality, morbidity, conversion rate and postoperative hospital stay in patients who underwent $L C$ for AC during the urgent (index) admission.
\end{abstract}

Keywords: Acute Cholecystitis(AC), Early cholecystectomy, Laparoscopic Cholecystectomy (LC) Bile duct injury incidence, Conversion rate.

\section{Introduction}

The most common surgical cause of acute abdominal pain in a patient admitted to a hospital anywhere in the world is acute appendicitis. The next most common cause in Africa is small-bowel obstruction; in the West it is acute cholecystitis.Gall stone disease accounts for majority of causes of Acute cholecystitis(9095\%).1 Cholelithiasis is a worldwide problem with an incidence risk of $10 \%-15 \%$ during life time.2 Of these most are silent. 3 Only $1-2 \%$ of asymptomatic patients develop serious symptoms or complications per year. Therefore only $1 \%$ of the patients require cholecystectomy .Surgeries on the gall bladder rank next to hernia repair and appendectomy worldwide. Gallbladder disease is the most costly digestive disorder4 In our daily practice, one third of the patients present beyond 72 hours and due to various reasons are managed conservatively with interval cholecystectomy to follow. There is an increased total hospitalization and subsequently increased cost in these patients. Furthermore, the subgroup of patients who do not respond to conservative treatment, as well as those who relapse while awaiting an interval cholecystectomy should be considered for early cholecystectomy.

For these reasons, a policy of performing a LC during the initial emergency/urgent admission for "all comers" with AC, regardless of time delay between its onset of symptoms and surgery was adopted. In view of this policy, we examined prospectively the impact of the duration of symptoms on mortality, morbidity, conversion rate and postoperative hospital stay in patients who underwent LC for AC during the urgent (index) admission. The aim of the study was to detect the impact of the time elapsed from onset of symptoms to operation on the conversion rate, morbidity, mortality with special attention to bile duct injury incidence and length of postoperative hospital stay. Inadequate knowledge of the course and relation of the biliary structures and its variations, compounded with poor visualization during open procedures account for the many postoperative complications. Laparoscopic cholecystectomy has revolutionized gall bladder surgery in the recent years because of magnification. Laparoscopic cholecystectomy (LC) has been established as the treatment of choice for the management of acute cholecystitis (AC) for the past 2 decades. Several prospective randomized trials suggest the superiority of early (within $72 \mathrm{~h}$ ) over the delayed (after a few weeks interval) intervention. This $72 \mathrm{~h}$ limit, however, is difficult to be kept in many cases for a variety of reasons, referring to both the patients and physicians.

\section{Aims And Objectives}

To evaluate the impact of the time lapse from the onset of symptoms to operation with respect to $\bullet$ Conversion rate (laparoscopic to open cholecystectomy) $\bullet$ Incidence of bile duct injury $\bullet$ Length of post-op hospital stay $\bullet$ Morbidity $\bullet$ Mortality.

\section{Materials And Methods}

All Cases admitted in the Department of General Surgery, KATURI General Hospital, Guntur, from October 2014 to October 2016, with features of AC for which LC is performed at the index admission. 2. Patients were diagnosed as $\mathrm{AC}$ when they had five out of the following six positive criteria: a. Persistent right upper quadrant pain b. Temperature $>37.5^{\circ} \mathrm{C}$ c. WBC $>10 \times 103 / \mathrm{L}$ d. Positive Murphy's sign e. Presence of 
gallstones on ultrasound in combination with wall thickening and/or fluid in the gallbladder fossa 3 . The diagnosis of AC was confirmed by intra operative findings \& pathologic findings 4. Patients with strong evidence of concomitant common bile duct stones were treated initially with preoperative Endoscopic retrograde cholangiopancreatography (ERCP), sphincterotomy and CBD clearance followed by LC. 5. Intra-operative cholangiogram was not performed in any of the cases 6 . Every effort was made to operate the patient as soon as possible, provided that any concomitant medical problem was previously dealt with. 7. Laproscopic cholecystectomy was attempted in all cases under general anaesthesia 8. Standard technique was used in all patients. 9. Judicious policy was always considered 10.The patients were divided into two groups according to the time between onset of symptoms and operation a. within 3 days (early group)-Group A, b. more than 4 days - Group B 11.All data including demographics, preoperative operative findings and postoperative information were collected prospectively into a computerized database. 12.Exclusion criteria includes pregnant women, pediatric and patients medically unfit for open cholecystectomy. 13. The aim of the study was to detect the impact of time elapsed from the onset of symptoms to operation on the conversion rate, morbidity, mortality, with special attention to bile duct injury incidence and length of post-operative hospital stay.

\section{Observation \& results}

1. Statistical analysis was done using SPSS 20 software. 2. Data is expressed as means and standard deviation for continuous variables $\&$ as percentages for categorical variables. 3. Comparisons of means were done by independent sample $\mathrm{T}$ Test and proportions by Fisher's exact test 4 . P value $<0.05$ was considered statistically significant.

Patient Groups Table no: 1 Patent Groups

\begin{tabular}{|l|l|l|l|}
\hline Patient Groups & Time & Number & \multirow{2}{*}{ Total } \\
\cline { 1 - 3 } Group A & With in 3 days & $\mathbf{4 8}$ & \multirow{2}{*}{71} \\
\hline Group B & More than 4 days & $\mathbf{2 3}$ & \\
\hline
\end{tabular}

Sex Ratio Table No: 2 Sex Ratio

\begin{tabular}{|l|l|l|l|l|}
\hline & Male & Female & Total & p \\
\hline Group A & 20 & 28 & 48 & \multirow{2}{*}{0.6146} \\
\hline Group B & $\mathbf{8}$ & 15 & 23 & \\
\hline Total & 28 & 43 & 71 & \\
\hline
\end{tabular}

Spillage Table No: 3 Spillage In Present Study

\begin{tabular}{|l|l|l|l|}
\hline & Group A & Group B & P \\
\hline Spillage & $\mathbf{1 2}$ & $\mathbf{1 4}$ & $\mathbf{0 . 0 0 7 6}$ \\
\hline $\mathrm{P}=0.0076$ is statistically significant
\end{tabular}

$\mathrm{P}=0.0076$ is statistically significant

Drain Use Table No: 4 Drain Use In Present Study

\begin{tabular}{|l|l|l|l|}
\hline & Group A & Group b & p \\
\hline Drain use & 16 & 13 & $\mathbf{1 3} 009$ \\
\hline
\end{tabular}

$\mathrm{p}$ value is extremely statistically significant.

Operative Time Table No: 5 Operative Time In Present Study

\begin{tabular}{|l|l|l|l|}
\hline & Group A & Group B & p \\
\hline Operative time in minutes & $\mathbf{1 1 4}+/-\mathbf{1 8 . 5 6}$ & $\mathbf{1 3 0}+/-\mathbf{1 5 . 6 5}$ & $\mathbf{0 . 0 0 0 9}$ \\
\hline
\end{tabular}

Drain Table No: 6. Drain Effect On Post Op Stay

\begin{tabular}{|l|l|l|l|}
\hline Drain & $\begin{array}{l}\text { Post Operative stay }(< \\
\text { 3days })\end{array}$ & $\begin{array}{l}\text { Post Operative stay } \\
(>3 \text { days })\end{array}$ & P value \\
\hline No & 41 & 1 & \multirow{2}{*}{0.1511} \\
\hline Yes & 25 & 4 & \\
\hline
\end{tabular}

Post Operative Complications

Table No: 7 Post Operative Complications

\begin{tabular}{|l|l|l|}
\hline Complications & Group A & Group B \\
\hline Wound infection & 3 & 2 \\
\hline Sub Hepatic Collection & 0 & 2 \\
\hline Bleeding & 0 & 0 \\
\hline Bile Leak & 0 & 0 \\
\hline Cholangitis & 0 & 0 \\
\hline Chest infection & 0 & 0 \\
\hline Peritonitis & 0 & 0 \\
\hline DVT & 0 & 0 \\
\hline
\end{tabular}


A Study on Impact of the Time Lapse from Onset of Symptoms in Acute Cholecystitis to ...

\begin{tabular}{|l|l|l|}
\hline Total & 3 & 4 \\
\hline
\end{tabular}

Impact Of Delay In Surgery On Outcome

Table No : 8 Impact of Delay In LC on Outcomes

\begin{tabular}{|l|l|l|l|l|}
\hline Outcome & Group A (N=48) & Group B (N=23) & $\begin{array}{l}\text { Whole } \\
\text { Cohort }\end{array}$ & P \\
\hline Morbidity & $\mathbf{3}(6.25 \%)$ & $\mathbf{4}(17.3 \%)$ & $7(9.85 \%)$ & $\mathbf{0 . 2 1 5 7}$ \\
\hline Mortality & 0 & 0 & 0 & 1 \\
\hline Post Operative Stay In Days & $2.08+/-1.84$ & $2.60+/-1.9$ & 2.25 & 0.2739 \\
\hline Conversion & 0 & 0 & 0 & 1.0 \\
\hline
\end{tabular}

\section{Discussion}

In our daily practice, one third of the patients present beyond 72 hours and due to various reasons are managed conservatively with interval cholecystectomy to follow. There is an increased total hospitalization and subsequently increased cost in these patients. Furthermore, the subgroup of patients who do not respond to conservative treatment, as well as those who relapse while awaiting an interval cholecystectomy should be considered for early cholecystectomy. For these reasons, a policy of performing a LC during the initial emergency/urgent admission for "all comers" with AC, regardless of time delay between its onset of symptoms and surgery is adopted. In view of this policy, the impact of the duration of symptoms on mortality, morbidity, conversion rate and postoperative hospital stay in patients who underwent LC for AC during the urgent (index) admission is assessed prospectively in the present study Exclusion criteria includes those patients who are medically unfit for open cholecystectomy.

Primary outcomes measured are morbidity (surgery-related morbidity), conversion rate, and mortality. Secondary outcomes measured are hospital stay, operation time, and any other adverse events that were not considered above (eg, wound infections,sub hepatic collections, Biliary leaks and deep vein thrombosis). If early intervention less than 72 hours after symptoms started - can be achieved, "oedema planes" present during this period allow the gall bladder to be dissected laparoscopically. Although it is desirable to operate within this time period, it is often difficult to do so in clinical practice. By the time inflammation has been present for more than 72 hours, maturation of the inflammatory changes with the consequent fibrosis, contraction, and adhesions making surgery potentially more difficult to dissect the gall bladder38 In literature Early cholecystectomy within 72 hours from the onset of symptoms is suggested to be the optimal timing to perform early laparoscopic cholecystectomy39 In the present study Mean operating time, spillage, drain, postoperative stay are compared in both Early and Delayed LC group.

\section{Mean Operating Time In Minutes}

Table No : 9 Mean Operating Time In Minutes in Present Study

\begin{tabular}{|c|c|c|c|}
\hline & Group A & Group B & Whole cohort \\
& $\mathbf{n}=48$ & $\mathbf{n}=\mathbf{2 3}$ & $\mathbf{n = 7 1}$ \\
\hline Operative Time & $114.18 \min$ & $\mathbf{1 3 0 . 1 7 3}$ & 119.36 \\
(in minutes) & 18.56 & 15.65 & $\mathbf{1 3 . 5 6}$ \\
\hline
\end{tabular}

The mean operating time in the whole cohort is 119.36 min This Mean operating time is used to calculate $\mathrm{p}$ value.

Table No : 10 Mean Operating Time Comparison in Present Study

\begin{tabular}{|c|c|c|c|c|}
\hline & Group A & Group B & Total & $\mathbf{p}$ \\
\hline Operative time $<120 \mathrm{~min}$ & 35 & 7 & 42 & \multirow[t]{2}{*}{0.0009} \\
\hline Operative time $>120 \mathrm{~min}$ & 13 & 16 & 29 & \\
\hline & 48 & 23 & 71 & \\
\hline
\end{tabular}

This difference in mean operating time is statistically significant $(\mathrm{P}<0.005)$ The mean operating time was more in group B owing to the intra operativeconstraints such as difficulty in gall bladder exposure and dense dhesions obscuring the anatomy of Calot's triangle, spillage of stones. Several randomized controlled prospective trials in literature havecompared the mean operating time between Early Laparoscopiccholecystectomy group and Delayed group and results were shown in the below table.

Table No : 11 Mean Operating Time Comparison in Literature

\begin{tabular}{|c|c|c|c|c|}
\hline Reference & Study type & $\begin{array}{l}\text { Early Laparoscopic } \\
\text { Cholecystectomy }\end{array}$ & $\begin{array}{l}\text { Delayed Laparoscopic } \\
\text { Cholecystectomy }\end{array}$ & Operating room time \\
\hline LO et al $^{\mathbf{i}}$ & RCT & 45 & 41 & 135 vs $105, p=0.2$ \\
\hline Johansson et ali & RCT & 74 & 53 & 98 vs 100 \\
\hline Lai et al ${ }^{\text {ii }}$ & RCT & 53 & 71 & 123 vs $107, p=0.04$ \\
\hline Kolla et al $^{\text {iv }}$ & RCT & 20 & 20 & 104 vs 93 \\
\hline
\end{tabular}

The interval for delayed cholecystectomy was more than 6 weeks in these studies. 
A Study on Impact of the Time Lapse from Onset of Symptoms in Acute Cholecystitis to ...

Table No : 12 Mean Operating Time \& Time Interval in Literature

\begin{tabular}{|l|l|l|l|l|}
\hline Reference & Study type & $\begin{array}{l}\text { Time interval for } \\
\text { Early Laparoscopic } \\
\text { Cholecystectomy }\end{array}$ & $\begin{array}{l}\text { Time interval } \\
\text { for Delayed } \\
\text { Laparoscopic } \\
\text { Cholecystectomy }\end{array}$ & $\begin{array}{l}\text { Operating } \\
\text { room time }\end{array}$ \\
\hline L O et al & i & RCT & $<72$ hours & $\begin{array}{l}\mathbf{8 - 1 2} \text { weeks } \\
135 \text { vs 105, } \\
\text { p=0.2 }\end{array}$ \\
\hline Johansson et al $^{\text {ii }}$ & RCT & $<48$ hours & $6-8$ weeks & $\mathbf{9 8}$ vs 100 \\
\hline Lai et al $^{\text {ii }}$ & RCT & $<24$ hours & $\mathbf{6 - 8}$ weeks & $\begin{array}{l}\mathbf{1 2 3} \text { vs 107, p= } \\
\mathbf{0 . 0 4}\end{array}$ \\
\hline Kolla et al $^{\text {iv }}$ & RCT & $<24$ hours & $\mathbf{6 - 8}$ weeks & $\mathbf{1 0 4}$ vs 93 \\
\hline
\end{tabular}

Delayed laparoscopic cholecystectomy allows maturation of the inflammatory changes with the consequent fibrosis, contraction, and adhesionsand decreased mean operative time in these sudies

Table No : 13 Mean Operating Time in Literature

\begin{tabular}{|l|l|l|l|l|}
\hline Name of the study & $\mathbf{n}$ & Early (minutes) & $\mathbf{n}$ & Delayed (minutes) \\
\hline Lai $^{29}$ & $\mathbf{5 3}$ & $\mathbf{1 2 2}$ & $\mathbf{5 1}$ & $\mathbf{1 0 6}$ \\
\hline LO $^{30}$ & 45 & 135 & 41 & $\mathbf{1 0 5}$ \\
\hline DAVILA & 27 & 71 & 36 & $\mathbf{5 0}$ \\
\hline KHAN & 22 & 87 & 21 & $\mathbf{8 5}$ \\
\hline JOHANSSON $^{31}$ & 74 & 98 & 71 & $\mathbf{1 0 0}$ \\
\hline KOLLA $^{32}$ & 20 & 104 & 20 & 93 \\
\hline YADAV & 25 & 107 & 25 & 76 \\
\hline GUL & 30 & 98 & 30 & $\mathbf{8 0}$ \\
\hline VERMA & 30 & 65 & 30 & 56 \\
\hline OZKARDE & 30 & 67 & 30 & 71 \\
\hline PRESENT STUDY & 48 & 114 & 23 & 130 \\
\hline
\end{tabular}

As per these studies the operation time was significantly reduced in the delayed group but this was not associated with differences in complications, conversions or post operative morbidity. In the present study the mean operating time was more in delayed laparoscopic group owing to the intra operative constraints such as difficulty in gall bladder exposure and dense adhesions obscuring the anatomy of Calot's triangle, spillage of stones.

\section{Operating Time Effect On Spillage In The Present Study}

Table No : 14 Operating time effect on spillage in the present study

\begin{tabular}{|l|l|l|l|l|}
\hline & No spillage & Spillage & Total & p \\
\hline $\begin{array}{l}\text { Operating time } \\
\text { (<120 minutes) }\end{array}$ & 31 & 11 & 42 & \\
\cline { 1 - 4 } $\begin{array}{l}\text { Operating time } \\
\text { (>120 minutes) }\end{array}$ & 14 & 15 & 29 & \multirow{2}{*}{0.0443} \\
\cline { 1 - 4 } Total & 45 & 26 & 71 & \\
\hline
\end{tabular}

In the present study increased operative time has statistically significant effect on spillage of stones. Increased mean operating time can be due to difficulty in dissection of Gall bladder from liver bed leading to perforation of gallbladder and spillage of stones. Increased Mean operating time may be due to adhesions or difficulty in the dissection of Calot's triangle.

\section{Operating Time Effect On Drain}

Table No : 15 Operating time effect on drain

\begin{tabular}{|l|l|l|l|l|}
\hline & No spillage & Spillage & Total & p \\
\cline { 1 - 4 } $\begin{array}{l}\text { Operating time } \\
\text { (<120 minutes) }\end{array}$ & 31 & 11 & 42 & \multirow{2}{*}{0.0443} \\
\cline { 1 - 4 } $\begin{array}{l}\text { Operating time } \\
\text { (>120 minutes) }\end{array}$ & 14 & 15 & 29 & \\
\hline Total & 45 & 26 & 71 & \\
\hline
\end{tabular}

Operating time has no statistical effect on placement of drain 
A Study on Impact of the Time Lapse from Onset of Symptoms in Acute Cholecystitis to ...

Operating Time Effect On Conversion

Table No : 16 Operating time effect on conversion in Present Study

\begin{tabular}{|l|l|l|l|}
\hline & No Conversion & Conversion & P \\
\hline Operating time $<120$ minutes & 42 & 0 & \multirow{2}{*}{1} \\
\hline Operating time $>120$ minutes & 29 & 0 & \\
\hline Total & 71 & 0 & 0 \\
\hline
\end{tabular}

In the present study Mean Operating time has no effect on conversion rate.

\section{Mean Operating Time Effect On Morbidity}

Table No : 17 Mean operating time effect on morbidity

\begin{tabular}{|l|l|l|l|l|}
\hline & Morbidity & No Morbidity & Total & P \\
\hline Operating time $<120$ minutes & 2 & 40 & 42 & \multirow{0}{0.1133}{} \\
\hline Operaing time $>120$ minutes & 5 & 24 & 29 & \\
\hline
\end{tabular}

In the present study Mean operating time has no effect on Morbidity.

Operating Time Effect On Post-Op Hospital Stay

Table No : 18 Operating time effect on post-op hospital stay

\begin{tabular}{|l|l|l|l|}
\hline & Post operative stay (<3days) & Post operative stay (>3days) & P \\
\hline Operative time $<120$ minutes & 40 & 2 & \multirow{2}{*}{0.392} \\
\hline Operative time $>120$ minutes & 26 & 3 & 7 \\
\hline Total & 66 & 5 & 7 \\
\hline
\end{tabular}

In present study Mean operating time has no effect on length of post operative stay.

Spillage Table No: 19 Spillage in Present Study

\begin{tabular}{|l|l|l|l|}
\hline & Group A & Group B & p \\
\hline \multirow{2}{*}{ Spillage } & 12 & 14 & \\
\cline { 2 - 4 } & $26 \%$ & $60 \%$ & $0.0076 \%$ \\
\hline
\end{tabular}

In the present study spillage of stones is stastically significant in the delayed group.

\section{Spillage In Literature}

Perforation of the gall bladder occurs fairly frequently during laparoscopic cholecystectomy and is reported in the range of $10 \%-40 \%$ in various series

Table No : 20 Spillage In Literature

\begin{tabular}{|l|l|l|l|}
\hline Series & $\begin{array}{l}\text { Laparoscopic } \\
\text { Cholecystectomy }\end{array}$ & Spilled Stones & $\begin{array}{l}\text { Postoperative } \\
\text { complications }\end{array}$ \\
\hline Schafer et al $^{40}$ & $\mathbf{1 0 1 7 4}$ & $\mathbf{5 8 1}(\mathbf{5 . 8 \%})$ & $\mathbf{8 ( 0 . 0 8 \% )}$ \\
\hline Memon et al $^{41}$ & $\mathbf{8 5 6}$ & $\mathbf{1 0 6}(\mathbf{1 2 . 3 \%})$ & $\mathbf{8 ( 0 . 5 8 \% )}$ \\
\hline Rice et al $^{42}$ & 1059 & 103 & $\mathbf{3}$ \\
\hline Diez et al $^{43}$ & 3686 & $\mathbf{2 5 4}$ & $\mathbf{1 2}$ \\
\hline${\text { Sarli et } \text { al }^{44}}$ & 1127 & 131 & - \\
\hline
\end{tabular}

\section{Spillage Effect On Drain Placement}

Table No : 21 Spillage Effect On Drain Placement

\begin{tabular}{|l|l|l|l|}
\hline Spillage & No Drain & Drain & P \\
\cline { 1 - 3 } No & 34 & 11 & \multirow{2}{*}{0.0004} \\
\hline Yes & 8 & 18 & \\
\hline Total & 42 & 29 & \\
\hline
\end{tabular}

Spillage has extremely statistically significant effect on drain placement.

In order to avoid complications subsequent to perforation of gall bladder, intra peritoneal drains have been placed prophylactically in the present study.

\section{Spillage Effect On Post Op Stay}

Table No : 22 Spillage Effect On Post Op Stay in Present Study

\begin{tabular}{|l|l|l|l|}
\hline Spillage & $\begin{array}{l}\text { Postoperative stay ( } \\
<3 \text { days })\end{array}$ & $\begin{array}{l}\text { Postoperative stay ( } \\
\text { >3days })\end{array}$ & p \\
\hline No & 44 & 1 & \multirow{2}{*}{0.0567} \\
\hline Yes & 22 & 4 & \\
\hline Total & 66 & 5 & \\
\hline
\end{tabular}


Spillage has not quite statistically significant effect on post op stay in our present study. In the present study Spillage of stones has no effect on length of post-operative stay In our present study Spillage of stones can be due to 1) increased operating time (as increased Mean operating time has statistical significance on spillage of stones. 2) Failure to use extraction retrieval bags.

\section{Prevention of spillage}

1. During surgery attempt should be made to avoid spillage. Dissection should be carried out carefully and proper identification of planes between wall of the gall bladder and surrounding structures should be done. 2. During extraction retrieval bags should be used to retrieve the gallbladder as it decreases the Chances of spillage.

\section{Drain Use}

Table No : 23 Drain Use in Present Study

\begin{tabular}{|l|l|l|l|l|}
\hline & Group A & Group B & Total & P \\
\hline Drain used & 16 & 13 & 29 & \multirow{2}{*}{0.0009} \\
\cline { 1 - 4 } No drain & 32 & 10 & 42 & \\
\cline { 1 - 4 } & 48 & 23 & 71 & \\
\cline { 1 - 5 } & &
\end{tabular}

In the present study Placement of drains in group B is extremely statistically significant. Regarding cholecystectomy, the major reason for drain placement is the fear of bile leakage that may lead to bile peritonitis; this is usually due to anaberrant bile duct and not slippage of the cystic duct ligature. ${ }^{45}$ Many surgeons still continue drainage for reasons based on traditional teaching and not on reliable facts and figures. The main motive behind this practice was the fear of missing complications such as Postoperative bleeding and Biliary peritonitis. One justification in literature for inserting a drainage tube after laparoscopic cholecystectomy is to deflate carbon-dioxide to reduce postoperative pain, although the use of a drainage tube in these cases was found to intensify postoperative pain rather than relieving it. 46

In the present study no preoperative guidelines for drain placement were instituted so it was not possible to know the surgeon's justification for drain insertion, but (1) intra operative adhesions (2) Prolonged operative time (3)spillage of stones (4)prophylactic drain placement in cases when complications are expected may be the underlying reasons. However in the present study in the delayed laparoscopic group mean operating time has no statistical significance on drain placement but spillage of stones has extremely statistical significance on drain placement.

\section{Drain Effect On Post Op Stay}

Table No : 24 Drain effect on post op stay in Present Study

\begin{tabular}{|l|l|l|l|}
\hline Drain & Post operative stay (<3days) & Post operative stay (>3days) & P \\
\hline Yes & 41 & 1 & \multirow{2}{*}{0.1511} \\
\hline No & 25 & 4 & \\
\hline Total & 66 & 5 & \\
\hline
\end{tabular}

Drain placement has no significant effect on post op stay In regards to hospital stay, In the present study surgeons who inserted prophylactic drains waited at least 24 hours before its removal. However in our study drain placement has no significant statistical effect on post op stay. Other retrospective studies in the literature have shown there was no added benefit for prophylactic drain insertion after cholecystectomy for acute calculous cholecystitis in non-complicated or in complicated cases.

\section{Conversion}

Table No : 25 Conversion Rate in Present Study

\begin{tabular}{|l|l|l|l|l|}
\hline & Group A & Group B & Whole Cohort & P \\
\hline Conversion & 0 & 0 & 0 & \multirow{2}{*}{1} \\
\hline No Conversion & 48 & 23 & 71 & \\
\hline Total & 48 & 23 & 71 & \\
\hline
\end{tabular}

The present study has no conversion rates in both the group ( $\mathrm{p}$ value is 1) Present study does not support the suggestion that timing of surgery affects conversion rates. Present study being a single centre small study conversion rates are statistically insignificant between the early and delayed groups 


\section{Mean Operating Time Effect On Conversion}

Table No : 26 Operating Time Effect on Conversion

\begin{tabular}{|l|l|l|l|}
\hline & Conversion & No Conversion & P \\
\hline \begin{tabular}{l|l|l|} 
Operating time $<120$ \\
minutes
\end{tabular} & 0 & 42 & \multirow{2}{*}{1} \\
\cline { 1 - 3 } $\begin{array}{l}\text { Operating time }>120 \\
\text { minutes }\end{array}$ & 0 & 29 & \\
\hline Total & 0 & 71 & \\
\hline
\end{tabular}

Mean operating time has no statistical effect on conversion rates in the present study. Results from other comparative non-randomized trials of early and delayed LC during the urgent admission for AC are rather conflicting and most of these however indicate a higher conversion rate for the delayed group, but no difference in morbidity. ${ }^{47}$

Table No : 27 Conversion Rates in Literature

\begin{tabular}{|c|c|c|c|}
\hline Conversion & $\begin{array}{l}\text { Early Laparoscopic } \\
\text { Cholecystectomy }\end{array}$ & $\begin{array}{l}\text { Delayed Laparoscopic } \\
\text { Cholecystectomy }\end{array}$ & $\mathbf{p}$ \\
\hline Lai et al $^{29}$ & 11 of 53 & 11 of 51 & 0.96 \\
\hline Lo et $\mathrm{al}^{30}$ & 5 of 45 & 9 of 41 & 0.51 \\
\hline Davila et al & 1 of 27 & 6 of 36 & 0.22 \\
\hline 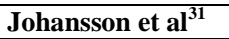 & 23 of 74 & 20 of 71 & 1.10 \\
\hline 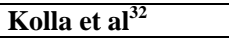 & 5 of 20 & 5 of 20 & 1.00 \\
\hline Yadav et al & 4 of 25 & 3 of 25 & 1.33 \\
\hline Macafee et al & 1 of 36 & 1 of 36 & 1.00 \\
\hline Gutt et al & 30 of 304 & 33 of 314 & 0.94 \\
\hline Verma et al & 3 of 30 & 4 of 30 & 0.75 \\
\hline Faizi et al & 4 of 25 & 12 of 25 & 1.50 \\
\hline Ozkardes et al & 4 of 30 & 0 of 30 & 9.00 \\
\hline Saber \& Hokkam & 3 of 61 & 1 of 59 & 2.90 \\
\hline Present study & 0 of 48 & 0 of 23 & 1 \\
\hline
\end{tabular}

However to design a randomized study to assess differences in outcomes between early and delayed laparoscopic cholecystectomy for acute cholecystitis where the conversion rate is taken as the primary outcome, for the study to detect $10 \%$ difference between groups with $80 \%$ power with $P<.05$, assuming a conversion rate of $10 \%$ in the most successful group, a total of 350 patients would need to be recruited. In present study total number of patients is 71.In the literature there are many established factors associated with an increased conversion rate such as obesity, multiple co morbidities, male sex, and inexperienced operator ${ }^{48}$

\section{Morbidity Wound Infections}

Table No: 28 Wound infections in Present Study

\begin{tabular}{|l|l|l|l|l|}
\hline & Group A $(\mathbf{n}=48)$ & Group B $(\mathbf{n}=\mathbf{2 3})$ & Whole Cohort $(\mathbf{n}=71)$ & P \\
\hline Wound infection & $\mathbf{3 ( 6 . 2 5 \% )}$ & $\mathbf{2}(\mathbf{8 . 6 9 \%})$ & $\mathbf{5}(\mathbf{7 . 0 4})$ & $\mathbf{0 . 6 5 6 3}$ \\
\hline
\end{tabular}

There is no statistically significant difference in wound infection between the two groups. In the present study timing of surgery has no effect on wound infections.

\section{Sub Hepatic Collection}

Table No: 29 Sub hepatic collection in Present Study

\begin{tabular}{|l|l|l|l|l|}
\hline Sub Hepatic Collection & Group A & Group B & Whole Cohort & p \\
\hline Yes & 0 & 2 & 2 & \multirow{2}{*}{0.1018} \\
\hline No & 48 & 21 & 69 & \\
\hline Total & 48 & 23 & 71 & \\
\hline
\end{tabular}

There is no statistical significant difference between the Early and Delayed group

\section{Bile Duct Injuries}

Table No: 30 Bile Duct Injuries In Present Study

\begin{tabular}{|l|l|l|l|}
\hline Bile duct injuries & Group A $(\mathbf{n}=\mathbf{4 8})$ & Group B $(\mathbf{n}=\mathbf{2 3})$ & P \\
\hline & $\mathbf{0}$ & $\mathbf{0}$ & $\mathbf{1}$ \\
\hline
\end{tabular}

Bile leaks were null between the two groups. As per the present study the relationship between timing of cholecystectomy and specific complications such as bile leaks was statistically insignificant, although the numbers in each group were small. 
Incidence of bile duct injuries in the literature was shown in the table

Table No: 31 Bile Duct Injuries in Literature

\begin{tabular}{|c|c|c|c|}
\hline Lai et $a^{29}$ & 0 of 53 & 0 of 51 & - \\
\hline Lo et $\mathrm{al}^{30}$ & 0 of 45 & 1 of 41 & 0.3 \\
\hline Davila et al & 0 of 27 & 0 of 36 & - \\
\hline Johansson et al $^{31}$ & 0 of 74 & 1 of 71 & 0.32 \\
\hline Kolla et al $^{32}$ & 1 of 20 & 0 of 20 & 3.00 \\
\hline Gul et al & 0 of 30 & 0 of 30 & - \\
\hline Verma et al & 0 of 30 & 0 of 30 & - \\
\hline Ozkardes et al & 1 of 30 & 0 of 30 & 3.00 \\
\hline Present study & 0 of 48 & 0 of 23 & 1.0 \\
\hline
\end{tabular}

Another issue of concern in laparoscopic treatment of AC is the presumed increased risk of bile duct injury when the procedure is performed beyond the early edematous phase of the first 48-72 h. It is possible that the majority of patients with AC who are deferred for interval LC because they are outside this "early window of chance" are faced with a "difficult" elective cholecystectomy after few weeks. Waiting for the gallbladder adhesions to dissolve and allowing maturation of acute inflammation, neo-vascularization, fibrosis, and contraction, making the dissection more difficult, as it has been proposed by others ${ }^{49}$ Present study data do not support this traditional belief, as there is no major bile duct injury in any of the patients. While inflammation in the early stages may not necessarily involve Calot's triangle structures, chronic inflammation may scar and distort it, making dissection in this critical area more difficult and prone to bile duct injuries in delayed groups.

\section{Mortality}

Table No: 32 Mortality in Present Study

\begin{tabular}{|l|l|l|l|}
\hline \multirow{3}{*}{ Mortality } & Group A $(\mathbf{n}=\mathbf{4 8})$ & Group B $(\mathrm{n}=23)$ & p \\
\cline { 2 - 4 } & 0 & 0 & 1 \\
\hline
\end{tabular}

In the present study there is no statistical significant difference between Early and Delayed cholecystectomy group A null mortality reported for both the groups recruited in the study reflectsa possibility of selection bias of the studied patients with the findings potentially inapplicable to the critically ill.

\section{Post Operative Stay}

Table No: 33 Post Operative Stay Comparison in Present Study

\begin{tabular}{|l|l|l|l|}
\hline \multirow{2}{*}{ Post Operative stay in days } & Group A $(\mathrm{n}=48)$ & Group B $(\mathrm{n}=23)$ & $\mathrm{p}$ \\
\cline { 2 - 4 } & $2.08+/-1.83$ & $2.60+/-1.9$ & 0.2739 \\
\hline
\end{tabular}

There is no significant statistical difference in Post operative stay between the Early laparoscopic cholecystectomy and Delayed laparoscopic cholecystectomy group. A reduction in total hospital stay confers socioeconomic and administrative advantages and occurs as a result of the procedure being undertaken during a single visit, despite the possibility of a single longer hospital stay during the emergency admission as opposed to two admissions for an interval laparoscopic cholecystectomy.Zhu B et al concluded that both early and late LC are safe for treating AC, but the operative difficulty of late LC is greater. Early LC is superior to Delayed LC as it tends to shorten the total length of hospital stay and is less Expensive $^{50}$.

\section{Overall Complications}

Table No: 34 Overall complications in present study

\begin{tabular}{|c|c|c|c|c|}
\hline Outcome & Group A $(n=48)$ & Group B $(n=23)$ & Whole Cohort $(n=71)$ & $\mathbf{p}$ \\
\hline Morbidity & 3 & 4 & 7 & 0.2029 \\
\hline Mortality & $\mathbf{0}$ & $\mathbf{0}$ & $\mathbf{0}$ & 1 \\
\hline $\begin{array}{l}\text { Post Operative hospital stay } \\
\text { (in days) }\end{array}$ & $2.08+/-1.84$ & $2.60+/-1.9$ & 2.25 & 0.2739 \\
\hline Conversion & $\mathbf{0}$ & $\mathbf{0}$ & $\mathbf{0}$ & 1.0 \\
\hline
\end{tabular}

\section{Over All Complications In Literature}

Table No: 35 Over All Complications In Literature

\begin{tabular}{|l|l|l|l|}
\hline Over all Complications & Early & Delayed & p \\
\hline Lai et al $^{29}$ & 5 of 53 & 3 of 51 & 1.60 \\
\hline${\text { Lo et } \mathbf{a l}^{30}}^{\text {Davila et al }}$ & 6 of 45 & 12 of 41 & 0.46 \\
\hline Khan & 5 of 27 & 13 of 31 & 0.44 \\
\hline Johansson et al $^{31}$ & 3 of 22 & 3 of 21 & 0.95 \\
\hline Present study & 13 of 74 & 7 of 71 & 1.78 \\
\hline & 3 of 48 & 4 of 23 & 1.0 \\
\hline
\end{tabular}


In the present study no significant difference in Morbidity between Early and Delayed groups was identified. Chandler et al found that there is no difference in the conversion rate or morbidity between the early group and the delayed group ${ }^{51}$ Johner A et al, proposed that, adoption of a policy in favor of early LC in acute cholecystitis will result in better patient quality of life and substantial savings to the Canadian health care system $^{52}$ Panagiotopoulou IG et al, concluded that there did not appear to be any difference in conversion or morbidity rates between early LC and delayed $\mathrm{LC}^{53} \quad \mathrm{Zhu} B$ et al concluded that both early and late LC are safe for treating $\mathrm{AC}$, but the operative difficulty of late LC is greater. Early LC is superior to late LC as it tends to shorten the total length of hospital stay and is less expensive.

\section{Summary And Conclusion}

\section{Present Study shows that the timing of cholecystectomy does not influence}

a. The conversion rate

b. Incidence of bile duct injury

c. Length of postoperative hospital stay

d. Morbidity

e. Mortality

No deaths were observed in any of the groups. There was no majorbile duct injury in any of the patients. Our data show that LC for AC during the index admission is safe and associated with a low morbidity and a low conversion rate. With expertise in laparoscopic surgery, every effort should be made to operate on all patients with AC during the index admission as soon as diagnosis is made and co-morbidities are dealt with, regardless of the time delay from the onset of symptoms.

This policy is safe, not associated with a higher conversion rate ormorbidity and results in an overall shorter hospitalization by avoiding readmissions.

\section{References}

[1]. Zielinski MD, Bannon MP.Current managementof small bowel obstruction. Adv Surg 2011;45:1-29

[2]. Shaffer EA.Gallstone disease:epidemiology of gall bladder stone disease.Best pract Res Clin Gastroenterol 2006;20(6):981-96

[3]. Halldestam I,Enell EL,Kullman E etal.Development of symptoms and complications in individuals with asymptomatic gallstones.Br J Surg 2004;91(6)734-8

[4]. Shaffer EA.Gallstone disease:epidemiology of gall bladder stone disease.Best pract Res Clin Gastroenterol 2006;20(6):981-96

[5]. Stinton LM,Myers RP,Shaffer EA .Epidemology of gall stones.Gastroenterol Clin North Am 2010:39(2):157-69,VII

[6]. Schwartz SL,Brunicardi FC.Schwartz priniciples of surgery, 9 th edition.Newyork:McGraw-Hill,Medical Pub.Divison;2010.p.1866,Xxi.

[7]. Moosman DA. Where and how to find the cystic artery during cholecystectomy. Surg Gynecol Obstet 1975;141:769. [PubMed: 1198315]

[8]. Chaib E,Kanas AF ,Galvao FH,et al.Bile duct confluence:anatomic variations and its classification.Surg Radiol Anat 2013 [ Epub ahead of print]

[9]. Zeigler KM,Zyromski NJ,Choledochoceles:are they choledochal cysts?Adv surg 2011;45:211-24

[10]. ShuklaPJ,Barreto SG,Kulakarni et al.Vascular anomalies encounterd during pancreatoduodenectomy:do they influence outcomes?Ann Surg Oncol 2010;17(1):186-93

[11]. Steiner CA ,Bass EB, Talamini MA, surgical rates and operative mortality for open and laproscopic cholecystectomy in mary land.N Engl J Med 1994;330(6): 403-8.

[12]. Orlando R 3rd ,Russell JC,Lynch J ,et al.Laproscopic cholecystectomy.A state wide experience.The Connecticut laproscopic cholecystectomy registry.Arch surg 1993;128(5):494-8

[13]. Ryu JK,Ryu KH,Kim KH. Clinical featurs of acute cholecystitis .J Clin Gastroenterol 2003;36(2):166-9.

[14]. Petersen JM,Knight TT.Gunshot cholecystitis.J Clin Gastroenterol 1995;21(4):320-2

[15]. Sjodahl R, et al, 1978: Pathogenesis of acute cholecystitis. Surg Gynecol Obstet 146:199-202.

[16]. Ryu JK,Ryu KH,Kim KH. Clinical featurs of acute cholecystitis .J Clin Gastroenterol 2003;36(2):166-9.

[17]. den Hoed PT, et al, 1998: Infections and bacteriological data after laparoscopic and open gallbladder surgery. J Hosp Infect 39:2737.

[18]. Gruber PJ,Silverman RA,Gottesfeld S,et al presence of fever and leucocytosis in acute cholecystitis.Ann Emerg Med 1996;28(3):273-7

[19]. McKernan B. Origin of laparoscopic cholecystectomy in the USA: Personal experience. World J Surg 1999;23:332-333. [PubMed: 10030855]

[20]. Lujan JA, Parrilla P, Robles R, Marin P, Torralba JA, Garcia-Ayllon J. Laparoscopic cholecystectomy vs open cholecystectomy in the treatment of acute cholecystitis. Arch Surg 133:173-175, 1998. [PubMed:9484730]

[21]. Hunter JG. Advanced laparoscopic surgery. Am J Surg 173:14-18, 1997.

[22]. [PubMed: 9046878]

[23]. Moore MJ, Bennett CL. The learning curve for laparoscopic cholecystectomy: The Southern Surgeons Club. Am J Surg 1995; 170:55. [PubMed: 7793496]

[24]. Merriam LT, Kanaan SA, Dawes LG, Angelos P, Prystowsky JB, Rege RV, Joehl RJ. Gangrenous cholecystitis: analysis of risk factors and experience with laparoscopic cholecystectomy. Surgery 1999;126:680-686

[25]. Kum CK, Goh PM, Isaac JR. Laparoscopic cholecystectomy for acute cholecystitis. Br J Surg 1994;81:1651-4

[26]. Koo KP, Thirlby RC. Laparoscopic cholecystectomy in acute cholecystitis: what is the optimal timing for operation? Arch Surg 1996;131:540 -5. 
[27]. Van der Linden W, Edlund G. Early versus delayed cholecystectomy: the effect of a change in management. Br J Surg 1981;68:753-7.

[28]. Kiviluoto T, Siren J, Luukkonen P, Kivilaakso E. Randomised trial of laparoscopic versus open cholecystectomy for acute and gangrenous cholecystitis. Lancet 1998;351:321-5.

[29]. Serralta AS, Bueno JL, Planells MR, Rodero DR. Prospective evaluation of emergency versus delayed laparoscopic cholecystectomy for early cholecystitis. Surg Laparosc Endosc Percutan Tech 2003;13:71-5.

[30]. Lai PBS, Kwong KH, Leung KL, et al. Randomised trial of early versus delayed laparoscopic cholecystectomy for acute cholecystitis. Br J Surg 1998;85:764 -7.

[31]. Lo CM, Liu Cl, Fan ST, Lai EC. Prospective randomized study of early versus delayed laparoscopic cholecystectomy for acute cholecystitis. Ann Surg 1998;227:461-7.

[32]. Johansson M, Thune A, Blomqvist A, et al. Management of acute cholecystitis in the laparoscopic era: results of a prospective, randomized clinical trial. J Gastrointest Surg 2003;7:642-5.

[33]. Kolla SB, Aggarwal S, Kumar A, et al. Early vs delayed laparoscopiccholecystectomy for acute cholecystitis. Surg Endosc 2004; 18:1323-7.

[34]. Chandler CF, Lane JS, Ferguson P, Thompson JE, Ashley SW. Prospective evaluation of early versus delayed laparoscopic cholecystectomy for treatment ofacute cholecystitis. Am Surg 2000; 66: 896-900

[35]. Johner A et al, Cost utility of early versus delayed laparoscopic cholecystectomy for acute cholecystitis, Surg Endosc, 2012 Jul 7.

[36]. Panagiotopoulou IG et al, Early laparoscopic cholecystectomy in a district general hospital: is it safe and feasible

[37]. Lu EJ,Curet MJ,El-sayed YY,et al.Medical vs surgical management of biliary tract disease in pregnancy.Am $\mathrm{J}$ surg 2004;188(6):755-9

[38]. Gilo NB,Amini D,Landy HJ.Appendicitis and cholecystitis in pregnancy.Clin Obstet Gynecol 2009;52 (4):586-96

[39]. Koo KP, Thirlby RC. Laparoscopic cholecystectomy in acute cholecystitis: what is the optimal timing for operation? Arch Surg 1996; 131:540-5

[40]. Chandler CF, Lane JS, Ferguson P, et al. Prospective evaluation of early versus delayed laparoscopic cholecystectomy for treatment of acute cholecystitis. Am Surg 2000;66:896 -900.

[41]. Schafer M, Suter C, Klaiber C, et al. Spilled gallstones after laparoscopic cholecystectomy. A relevant problem? A retrospective analysis of 10,174 laparoscopic cholecystectomies. Surg Endosc1998;12:291-3

[42]. Memon MA, Deeik RK, Maffi TR, et al. The outcome of unretrieved gallstones in the peritoneal cavity d uring laparoscopic cholecstectomy. A prospective analysis. Surg Endosc1999;13:848-57

[43]. Rice DC, Memon MA, Jamison RL, et al. Long term consequences of intraoperative spillage of bile and gall stones during laparoscopic cholecystectomy. J Gastrointest Surg 1997;1:85-91.

[44]. Diez J, Arozamena C, Gutierez L, et al. Lost stones during laparoscopic cholecstectomy. HPB Surg 1998;11:105-8. discussion 1089

[45]. Sarli L, Pietra N, Costi R, et al. Gallbladder perforation during laparoscopic cholecystectomy. World J Surg 1999;23:1186-90

[46]. Diez JA, Pujato MR, Ferreres AR. The need of drainage after cholecystectomy. HPB Surg. 1990;3:5-10.

[47]. Picchio M, De Angelis F, Zazza S, Di Filippo A, Mancini R, Pattaro G, et al. Drain after elective laparoscopic cholecystectomy. A randomized multicentre controlled trial. Surg Endosc. 2012;26:2817-22.

[48]. Knight JS, Mercer SJ, Somers SS, Walters AM, Sadek SA, Toh SK. Timing of urgent laparoscopic cholecystectomy does not influence conversion rate. Br J Surg 2004; 91: 601-604

[49]. Rattner DW, Ferguson C, Warshaw AL. Factors associated with successful laparoscopic cholecystectomy for acute cholecystitis. Ann Surg 1993;217:233-6.

[50]. Serralta AS, Bueno JL, Planells MR, Rodero DR. Prospective evaluation of emergency versus delayed laparoscopic cholecystectomy for early cholecystitis.Surg Laparosc Endosc Percutan Tech 2003; 13: 71-75

[51]. Zhu B et al, Comparison of Laparoscopic Cholecystectomy for Acute Cholecystitis within and beyond 72 hours of symptom onset during emergency admission, World J Surg, 2012 July 18.

[52]. Chandler CF, Lane JS, Ferguson P, Thompson JE, Ashley SW. Prospective evaluation of early versus delayed laparoscopic cholecystectomy for treatment of acute cholecystitis. Am Surg 2000; 66: 896-900

[53]. Johner A et al, Cost utility of early versus delayed laparoscopic cholecystectomy for acute cholecystitis, Surg Endosc, 2012 Jul 7.

[54]. Panagiotopoulou IG et al, Early laparoscopic cholecystectomy in a district general hospital: is it safe and feasible. 